\title{
MANEJO DO ETILENO EM AMEIXAS 'LAETITIA' ARMAZENADAS SOB ATMOSFERAS CONTROLADA E MODIFICADA ATIVA ${ }^{1}$
}

\author{
THAIS ROSELI CORREA ${ }^{2}$, CRISTIANO ANDRÉ STEFFENS ${ }^{2}$, \\ HÉLIO TANAKA ${ }^{2}$ CASSANDRO VIDAL TALAMINI DO AMARANTE ${ }^{2}$, \\ AURI BRACKMANN ${ }^{3}$, ROGÉRIO DE OLIVEIRA ANESE ${ }^{3}$
}

RESUMO - O objetivo deste trabalho foi avaliar o efeito de condições de atmosfera controlada (AC) e atmosfera modificada (AM) ativa (filme PEBD de $40 \mu \mathrm{m}$, com duas perfurações de 1,0 mm de diâmetro), associadas ao manejo do etileno, sobre a manutenção da qualidade em ameixas 'Laetitia'. Os tratamentos avaliados consistiram no armazenamento refrigerado $\left(60\right.$ dias a $\left.0,5 \pm 0,1^{\circ} \mathrm{C}\right)$ em: atmosfera refrigerada (AR; $\left.21,0 \mathrm{kPa} \mathrm{O}_{2}+<0,03 \mathrm{kPa} \mathrm{CO}_{2}\right) ; \mathrm{AM} ; \mathrm{AM}+$ baixo etileno (BE); $\mathrm{AC}$; e AC + 1-MCP $\left(1,0 \mu \mathrm{L} \mathrm{L}^{-1}\right)$. As pressões parciais de $\mathrm{O}_{2}+\mathrm{CO}_{2}(\mathrm{kPa})$ foram de $1,0+1,0$ e 2,5 +<0,1, em AC e AM, respectivamente. Os frutos armazenados em AC, independentemente do tratamento com 1-MCP, apresentaram retardo no amadurecimento, quando comparados aos frutos em AR. Contudo, os melhores resultados para a manutenção da textura da polpa e da acidez titulável foram obtidos em AC + 1-MCP. Os tratamentos não interferiram para a incidência de podridões, rachaduras e degenerescência da polpa. Frutos dos tratamentos AM + BE e AC + 1-MCP apresentaram menor intensidade de escurecimento da polpa e maior aceitabilidade quanto à cor e ao sabor na análise sensorial em relação àqueles armazenados em AR.

Termos para indexação: Prunus salicina, degenerescência da polpa, pós-colheita, qualidade, 1-MCP.

\section{'LAETITIA' PLUMS STORED IN CONTROLLED ATMOSPHERE AND ACTIVE MODIFIED ATMOSPHERE PACKING WITH ETHYLENE MANAGEMENT}

\begin{abstract}
The objective of this study was to evaluate the effect of controlled atmosphere (CA) and active modified atmosphere packing (MAP) [LDPE film $(40 \mu \mathrm{m})$, with two perforations (diameter $=1.0$ $\mathrm{mm}$ ) with ethylene management, on quality preservation of 'Laetitia' plums. The cold storage (60 days at $0.5 \pm 0.1^{\circ} \mathrm{C}$ ) treatments evaluated were: stored atmosphere $\left(\mathrm{SA} ; 21.0 \mathrm{kPa} \mathrm{O}_{2}+<0.03 \mathrm{kPa} \mathrm{CO}_{2}\right)$; MAP; MAP + low ethylene (LE); CA; and CA + treatment with 1-MCP $\left(1,0 \mu \mathrm{L} \mathrm{L}^{-1}\right)$. The partial pressures of $\mathrm{O}_{2}+\mathrm{CO}_{2}$ $(\mathrm{kPa})$ were $1.0+1.0$ and $2.5+<0.1$, in CA and MAP, respectively. Fruits stored in CA, regardless of ethylene removal, showed ripening delay compared to fruit in CS. However, the best preservation of flesh texture and titratable acidity was achieved in CA +1 -MCP. The incidences of decay, skin cracking and flesh browning were not different between treatments. Fruits stored in MAP + LE and CA + 1-MCP had lower internal darkening and higher acceptability for color and taste compared to fruit stored in SA.
\end{abstract}

Index terms: Prunus salicina, flesh browning, postharvest, quality, 1-MCP.

\footnotetext{
${ }^{1}$ (Trabalho 171-10). Recebido em: 20-07-2010. Aceito para publicação em: 01-12-2010.

${ }^{2}$ Universidade do Estado de Santa Catarina (UDESC), Centro de Ciências Agroveterinárias (CAV), Departamento de Agronomia. Av. Luiz de Camões, 2090, Bairro Conta Dinheiro, CEP 88520-000, Lages-SC, Brasil. E-mails: thaisroselicorrea@hotmail.com; steffens@cav.udesc.br; tanaka.helio@gmail.com; amarante@cav.udesc.br

${ }^{3}$ Universidade Federal de Santa Maria (UFSM), Núcleo de Pesquisa em Pós-Colheita (NPP), Santa Maria-RS, Brasil. E-mail: brackman@ccr.ufsm.br; rogerio_anese@yahoo.com.br
} 


\section{INTRODUÇÃO}

Ameixas 'Laetitia' apresentam um curto período de oferta na entressafra, devido à elevada taxa metabólica, que ocasiona rápido amadurecimento dos frutos. No entanto, para a regulação da oferta e dos preços do produto, o armazenamento apresenta-se como alternativa mais viável (BRACKMANN et al., 2005a).

Dentre os sistemas de armazenamento, o mais utilizado é o armazenamento refrigerado, pois diminui o metabolismo do fruto e evita a rápida deterioração (BRACKMANN et al., 2003). A redução da temperatura é o principal fator que influencia na manutenção da qualidade dos frutos durante o armazenamento (STEFFENS et al., 2007). Porém, $\mathrm{o}$ armazenamento refrigerado prolongado resulta em ameixas com baixa firmeza de polpa e com incidência de degenerescência da polpa, o que pode reduzir a aceitabilidade pelo consumidor (MANGANARIS et al., 2008; ALVES et al., 2009a).

Outras técnicas de armazenamento, como a atmosfera controlada (AC), podem complementar os efeitos do frio, pois o controle da pressão parcial dos gases é efetivo na redução de perdas e no aumento da vida pós-colheita de ameixas (BRACKMANN et al., 2005a). O sistema de atmosfera modificada (AM) apresenta-se mais vantajoso em relação a AC por ser de uso mais prático e menos oneroso (STEFFENS et al., 2009). Este sistema de armazenamento pode aumentar o período de oferta da ameixa, bem como possibilitar a comercialização de frutos com melhor qualidade durante a entressafra (STEFFENS et al., 2009).

Em condições de armazenamento, frutos climatéricos, como a ameixa, apresentam sensibilidade ao etileno, hormônio envolvido na antecipação da senescência de frutos (JACOMINO et al., 2002). Em ameixas 'Laetitia' foi verificado que a presença do etileno altera a qualidade destes frutos, causando rápida perda na firmeza de polpa, redução na acidez e aumento no escurecimento da polpa (ALVES et al., 2009a), sendo importante o uso de alternativas para reduzir os efeitos do etileno durante o armazenamento.

Dentre as técnicas para remoção do etileno do ambiente de armazenamento, pode-se fazer uso de sachês contendo pellets impregnados com permanganato de potássio $\left(\mathrm{KMnO}_{4}\right)$, que promove a oxidação do etileno à água, gás carbônico, dióxido de manganês e potássio (WILLS; WARTON, 2004). Em maçãs 'Gala', o uso desta técnica diminuiu a concentração de etileno no ambiente de armazenamento e manteve a cor verde e a firmeza de polpa
(AMARANTE; STEFFENS, 2009).

Inibidores da ação do etileno, como o 1-metilciclopropeno (1-MCP), também podem oferecer excelentes resultados na manutenção da qualidade de frutos. O 1-MCP é um antagonista da ação do etileno (BLANKENSHIP; DOLE, 2003), e a sua aplicação retarda o amadurecimento, diminui a incidência da degenerescência de polpa e estende o período de armazenagem em ameixas (KHAN; SINGH, 2009; ALVES et al., 2009b). Em maçãs 'Gala', o tratamento com 1-MCP proporcionou maior firmeza da polpa e maior acidez, além de manter a cor de fundo da epiderme dos frutos (BRACKMANN et al., 2004).

O presente trabalho foi realizado com o objetivo de avaliar o efeito do uso de AC e AM ativa, associadas ao manejo do etileno e do 1-MCP, sobre a manutenção da qualidade de ameixas 'Laetitia'.

\section{MATERIAL E MÉTODOS}

O experimento foi conduzido no ano de 2009 , com ameixas da cultivar Laetitia provenientes de um pomar comercial localizado no município de LagesSC. Os frutos foram colhidos e levados ao laboratório, onde foram selecionados, eliminando-se aqueles de pequeno calibre, com podridões, ferimentos, lesões, defeitos ou dano mecânico, procedendo-se então à homogeneização das unidades experimentais.

$\mathrm{O}$ delineamento experimental utilizado foi o inteiramente casualizado, com quatro repetições de 20 frutos por tratamento. Os tratamentos avaliados consistiram no armazenamento refrigerado em: atmosfera refrigerada (AR; 21,0 $\mathrm{kPa} \mathrm{O}_{2}+<0,03 \mathrm{kPa}$ $\mathrm{CO}_{2}$ ); atmosfera modificada (AM); $\mathrm{AM}+$ baixo etileno (BE); atmosfera controlada (AC); e $\mathrm{AC}+$ tratamento com 1-MCP $\left(1,0 \mu \mathrm{L} \mathrm{L}^{-1}\right)$. As pressões parciais de $\mathrm{O}_{2}+\mathrm{CO}_{2}(\mathrm{kPa})$ foram de $1,0+1,0$, em AC, e, em média, 2,5 $+<0,1$, em AM. A embalagem para atmosfera modificada possuía uma espessura de $40 \mu \mathrm{m}$. Os frutos de todos os tratamentos foram armazenados sob temperatura de $0,5 \pm 0,1^{\circ} \mathrm{C}$ e umidade relativa do ar de $95 \pm 2 \%$.

As pressões parciais dos gases nos tratamentos em $\mathrm{AC}$ foram obtidas mediante a diluição do $\mathrm{O}_{2}$ no ambiente de armazenamento com injeção de $\mathrm{N}_{2}$, proveniente de um gerador de nitrogênio, que utiliza o princípio "Pressure Swing Adsorption" (PSA), e posterior injeção de $\mathrm{CO}_{2}$, provenientes de cilindros de alta pressão, até atingir o nível preestabelecido no tratamento. A manutenção das pressões parciais desejadas dos gases, nas diferentes condições de armazenamento, que variavam em função da respiração dos frutos, foi realizada diariamente, com o uso de equipamento automático para controle de gases da 
marca Kronenberger/Climasul. Quando os níveis do $\mathrm{CO}_{2}$ e $\mathrm{O}_{2}$ não estavam adequados, o equipamento procedia à correção das pressões parciais até os níveis preestabelecidos. $\mathrm{O} \mathrm{O}_{2}$ consumido pela respiração foi reposto por meio da injeção de ar atmosférico nas minicâmaras, e o $\mathrm{CO}_{2}$ em excesso foi absorvido por uma solução de hidróxido de potássio (40\%), através da qual foi circulado o ar do ambiente de armazenamento.

No tratamento com baixa concentração de etileno $\left(<0,04 \mu \mathrm{L} \mathrm{L}^{-1}\right)$, foi realizada a absorção química desse gás no interior da embalagem, por meio da adição de sachês (um sachê para cada três quilos de frutos) contendo $\mathrm{KMnO}_{4}$.

Para o tratamento com 1-MCP, foi utilizado o produto comercial SmartFresh ${ }^{\circledR}(0,14 \%$ de $1-\mathrm{MCP}$ na formulação pó), na concentração de $1,0 \mu \mathrm{LL}^{-1}$. O produto foi solubilizado em água dentro de um recipiente hermético, em condição ambiente, e, posteriormente, esta solução foi transferida para uma placa de Petri que foi colocada dentro de uma minicâmara com volume de $180 \mathrm{~L}$, hermeticamente fechada. Os frutos ficaram expostos a este tratamento durante 24 horas.

As características físicas e químicas antes do armazenamento foram: firmeza de polpa de $34,4 \mathrm{~N}$, sólidos solúveis (SS) de $9,2{ }^{\circ}$ Brix e acidez titulável (AT) de 25,8 meq $100 \mathrm{~mL}^{-1}$.

Os frutos foram armazenados sob refrigeração durante 60 dias, as análises foram realizadas no momento da saída da câmara e após 3 dias de exposição a condições ambiente $\left(\right.$ a $20 \pm 2{ }^{\circ} \mathrm{C} / 60 \pm 5 \%$ de UR ) para simulação do período de comercialização. No momento da saída da câmara, os frutos foram analisados quanto à taxa respiratória e à produção de etileno, aos índices de cor vermelha, de cor de fundo da epiderme e de incidência de podridões e rachaduras. Após três dias em condição ambiente, adicionalmente, foram avaliados a AT, firmeza de polpa, SS, atributos de textura, intensidade de escurecimento da polpa e incidência de degenerescência da polpa, conforme descrito em Alves et al. (2009a).

A intensidade de escurecimento da polpa foi avaliado por meio de um colorímetro Minolta, modelo CR 400, na região mediana da polpa dos frutos, sendo os resultados expressos em luminosidade $[(L$, em valores de 0 (preto) a 100 (branco)].

A análise sensorial foi realizada com um painel não treinado, constituído de 23 avaliadores, que analisaram os frutos quanto ao sabor e à cor da polpa. Foram atribuídos os conceitos ótimo, bom, regular e ruim para o sabor. Com relação à cor da polpa, os frutos foram enquadrados em aceitáveis ou não aceitáveis para o consumo.

Os dados foram submetidos à análise da va- riância (ANOVA), com o auxílio do programa SAS (SAS Institute, 2002). Dados em percentagem foram transformados pela fórmula arcsen $[(x+0,5) / 100]^{1 / 2}$ antes de serem submetidos à ANOVA. Para a comparação das médias, adotou-se o teste de Tukey $(\mathrm{p}<0,05)$.

\section{RESULTADOS E DISCUSSÃO}

Os armazenamentos em AC, com ou sem tratamento com 1-MCP, e em AM + BE proporcionaram menores taxas respiratórias dos frutos no momento da saída da câmara, em relação aos frutos armazenados em AR e AM sem absorção de etileno (Tabela 1). Após três dias de exposição dos frutos em condição ambiente, apenas os frutos armazenados em AC mantiveram menor taxa respiratória (Tabela 1). $\mathrm{O}$ efeito da $\mathrm{AC}$ sobre a respiração celular resulta da menor atividade de enzimas glicolíticas e do ciclo de Krebs sob condições de baixas pressões parciais de $\mathrm{O}_{2}$ e altas pessões parciais de $\mathrm{CO}_{2}$ (BRACKMANN et al., 2005b). Em AM, como a redução dos níveis de $\mathrm{O}_{2}$ decorre da atividade respiratória dos frutos e da restrição do filme às trocas gasosas (STEFFENS et al., 2007), o efeito do baixo $\mathrm{O}_{2}$ não ocorreu desde o início do armazenamento (dados não apresentados). Possivelmente, o uso do absorvedor de etileno em AM contribuiu para a redução da atividade respiratória dos frutos, conforme observado em maçãs 'Gala' armazenadas em frigoconservação (AMARANTE; STEFFENS, 2009).

Não foi possível detectar produção de etileno na saída da câmara em todos os tratamentos (Tabela 1). Aos três dias em condição ambiente, a taxa de produção de etileno foi menor nos frutos armazenados nas condições de AC e AM, independentemente do manejo do etileno, quando comparados aos frutos armazenados em AR (Tabela 1). A menor taxa de produção de etileno em frutos armazenados nessas condições deve estar relacionada à menor oxidação do ACC a etileno, devido ao baixo $\mathrm{O}_{2}$ (BLANKENSHIP;DOLE, 2003). Saquet e Streif (2002) verificaram redução na taxa de produção de etileno com a diminuição da pressão parcial de $\mathrm{O}_{2}$ em diversas cultivares de maçãs. Adicionalmente, em $\mathrm{AC}, \mathrm{o} \mathrm{CO}_{2}$ pode reduzir o $\mathrm{pH}$ da célula, podendo reduzir a atividade da ACC oxidase e, portanto, a biossíntese do etileno (GORNY; KADER, 1994).

$\mathrm{O}$ armazenamento $\mathrm{AC}+1 \mathrm{MCP}$ manteve os maiores valores de firmeza de polpa e dos atributos de textura (forças para ruptura da epiderme e compressão) dos frutos (Tabela 2), indicando que o 1-MCP, associado aos efeitos do baixo $\mathrm{O}_{2}$ e de $1,0 \mathrm{kPa} \mathrm{CO}$ em AC, mantém melhor consistência 
da polpa e retarda o amadurecimento dos frutos. A maior firmeza de polpa em ameixas tratadas com 1-MCP, quando comparadas com as não tratadas, também foi observada em outros trabalhos (MENNITI; GREGORI et al., 2006; KHAN; SINGH 2009). Esse efeito do 1-MCP na manutenção destes atributos está associado à redução da atividade das enzimas pectolíticas, devido à redução da ação do etileno (JACOMINO et al., 2002).

Os frutos armazenados em AC e AM, independentemente do manejo do etileno, apresentaram menor ICV e maior $h^{\circ}$ no lado menos vermelho, tanto no momento da saída da câmara quanto após três dias de simulação de vida de prateleira, quando comparados aos frutos em AR (Tabela 3). Esses resultados demonstram que o armazenamento em AM ou AC retardou os processos responsáveis pela evolução da cor em ameixas. Nava et al. (2002) observaram menor degradação da cor da epiderme em pêssegos armazenados em AC, quando comparados ao armazenamento em AR. Esses autores afirmam que isto ocorre, possivelmente, devido à redução na atividade de clorofilases, bem como pela menor síntese de pigmentos antociânicos e carotenoides. Alves et al. (2009b) não observaram diferenças quanto à evolução da cor vermelha em ameixas 'Laetitia' submetidas à aplicação de 1-MCP, afirmando que isto pode ser um indicativo de que o etileno não está diretamente relacionado com a mudança de coloração, corroborando os resultados obtidos no presente trabalho.

Os maiores valores de AT foram obtidos nos frutos do tratamento AC + 1-MCP (Tabela 3). Esses resultados demonstram o efeito do uso de 1-MCP na manutenção da AT de ameixas, estando de acordo com resultados obtidos por Luo et al. (2009). Segundo estes autores, a inibição da ação do etileno retarda o declínio pós-colheita da acidez. Argenta et al. (2001) afirmam que alterações associadas à maturação de frutos, como a redução na AT, é resultado de processos fisiológicos regulados pela produção de etileno em frutos climatéricos.

Os teores de SS e a incidência de podridões e rachaduras não diferiram entre os tratamentos, tendo valores médios de $9,48 \%$ para incidência de podridões na saída da câmara e $21,16 \%$ após três dias de exposição à condição ambiente, e quanto à incidência de rachaduras, os valores médios na saída da câmara foram de $17,72 \%$, e após três dias de exposição à condição ambiente, não houve incidência de rachaduras (dados não apresentados).

Os frutos de todos os tratamentos apresentaram degenerescência de polpa, não ocorrendo diferenças quanto à incidência deste distúrbio entre os mesmos (Tabela 3). Resultados semelhantes foram encontrados por Alves et al. (2009b), que não encontraram diferenças quanto à ocorrência da degenerescência de polpa em ameixas 'Laetitia' submetidas a diferentes temperaturas e ao tratamento com 1-MCP. A alta incidência de degenerescência de polpa em ameixas desta cultivar, armazenadas em AR e AM, também foi verificada por Steffens et al. (2009). Segundo Argenta et al. (2003), ameixas 'Laetitia' desenvolvem degenerescência de polpa durante o armazenamento refrigerado a $0,5^{\circ} \mathrm{C}$, principalmente quando a duração é superior a 30 dias. Este distúrbio fisiológico em frutos pode ser decorrente da redução do metabolismo energético e do conteúdo de fosfolipídios, com consequente descompartimentalização intracelulares (SAQUET et al., 2003; PEDRESCHI et al., 2009.

Apesar da elevada incidência de degenerescência de polpa em todos os tratamentos, foi verificado menor escurecimento (maior valor de $L$ ) da polpa nos frutos dos tratamentos AM + BE, AC e AC + 1-MCP (Tabela 3). Esse resultado demonstra que a remoção ou a inibição da ação do etileno retardam o desenvolvimento desse distúrbio fisiológico, conforme observado por Alves et al. (2009a). Segundo estes autores, além do etileno, o aumento na temperatura e no tempo de armazenamento também predispõe a ocorrência deste distúrbio em ameixas 'Laetitia'.

$\mathrm{Na}$ avaliação sensorial, as ameixas 'Laetitia' armazenadas em AR apresentaram rejeição superior a $90 \%$, quando avaliadas em termos de cor da polpa. Os tratamentos $\mathrm{AM}+\mathrm{BE}$ e $\mathrm{AC}+1-\mathrm{MCP}$ proporcionaram aceitabilidade dos frutos superior a $50 \mathrm{e}$ $80 \%$, respectivamente. Com relação ao sabor, os frutos armazenados nessas condições apresentaram aceitabilidade de 70\%. Esses resultados evidenciam que o manejo do etileno durante o armazenamento exerce boa influência na aceitabilidade do fruto pelo consumidor, como resultado da preservação do sabor e da aparência. 
TABELA 1 - Taxas respiratórias e de produção de etileno em ameixas 'Laetitia', após 60 dias em diferentes sistemas de armazenamento refrigerado $\left(0,5 \pm 0,1^{\circ} \mathrm{C} / 95 \pm 2 \%\right.$ UR), seguido de três dias em condição ambiente $\left(20 \pm 2^{\circ} \mathrm{C} / 60 \pm 5 \%\right.$ UR).

\begin{tabular}{lcc}
\hline \multicolumn{1}{c}{ Sistema de armazenamento } & $\begin{array}{c}\text { Taxa respiratória } \\
\left(\mathrm{nmol} \mathrm{CO} \mathrm{kg}^{-1} \mathrm{~s}^{-1}\right)\end{array}$ & $\begin{array}{c}\text { Taxa produção de etileno } \\
\left(\mathrm{pmol} \mathrm{kg}^{-1} \mathrm{~s}^{-1}\right)\end{array}$ \\
\hline & $403,8 \mathrm{a}$ & Saída da câmara \\
$\mathrm{AR}$ & $401,7 \mathrm{a}$ & $\mathrm{ND}$ \\
$\mathrm{AM}$ & $337,8 \mathrm{~b}$ & $\mathrm{ND}$ \\
$\mathrm{AM}+\mathrm{BE}$ & $338,8 \mathrm{~b}$ & $\mathrm{ND}$ \\
$\mathrm{AC}$ & $319,6 \mathrm{~b}$ & $\mathrm{ND}$ \\
$\mathrm{AC}+1-\mathrm{MCP}$ & 10,8 & - \\
\hline $\mathrm{CV}(\%)$ & Após três dias em temperatura ambiente \\
$\mathrm{AR}$ & $527,01 \mathrm{a}$ & $0,42 \mathrm{a}$ \\
$\mathrm{AM}$ & $501,61 \mathrm{a}$ & $0,02 \mathrm{~b}$ \\
$\mathrm{AM}+\mathrm{BE}$ & $493,75 \mathrm{a}$ & $0,01 \mathrm{~b}$ \\
$\mathrm{AC}$ & $320,18 \mathrm{~b}$ & $0,01 \mathrm{~b}$ \\
$\mathrm{AC}+1-\mathrm{MCP}$ & $361,14 \mathrm{~b}$ & $0,01 \mathrm{~b}$ \\
$\mathrm{CV}(\%)$ & 10,5 & 6,3 \\
\hline
\end{tabular}

Médias seguidas pela mesma letra na vertical não diferem entre si, pelo teste de Tukey $(\mathrm{p}<0,05)$. AR: atmosfera refrigerada $(21 \mathrm{kPa}$ $\mathrm{O}_{2}+<0,03 \mathrm{kPa} \mathrm{CO}$ ); AM: atmosfera modificada (PEBD perfurado com absorvedor de $\mathrm{CO}_{2}$, com 2,5 $\mathrm{kPa} \mathrm{O}+<0,1 \mathrm{kPa} \mathrm{CO}$ ); $\mathrm{AC}$ : atmosfera controlada $\left(1 \mathrm{kPa} \mathrm{O}_{2}+1 \mathrm{kPa} \mathrm{CO}_{2}\right)$. BE: baixo etileno; e 1-MCP: 1 -metilciclopropeno $\left(1 \mu \mathrm{L} \mathrm{L}^{-1}\right) *^{2} \mathrm{ND}=$ não detectado.

TABELA 2 - Firmeza de polpa e atributos de textura em ameixas 'Laetitia', após 60 dias em diferentes sistemas de armazenamento refrigerado $\left(0,5 \pm 0,1^{\circ} \mathrm{C} / 95 \pm 2 \% \mathrm{UR}\right)$, avaliados depois de três dias em condição ambiente $\left(20 \pm 2^{\circ} \mathrm{C} / 60 \pm 5 \%\right.$ UR).

\begin{tabular}{lcccc}
\hline Sistema de armazenamento & $\begin{array}{c}\text { Firmeza de } \\
\text { polpa }(\mathrm{N})\end{array}$ & $\begin{array}{c}\text { Força para } \\
\text { ruptura } \\
\text { da casca }(\mathrm{N})\end{array}$ & $\begin{array}{c}\text { Força para } \\
\text { penetração } \\
\text { da polpa }(\mathrm{N})\end{array}$ & $\begin{array}{c}\text { Força para } \\
\text { compressão } \\
\text { do fruto }(\mathrm{N})\end{array}$ \\
\hline $\mathrm{AR}$ & $19,01 \mathrm{~b}$ & $4,33 \mathrm{c}$ & $0,81 \mathrm{c}$ & $61,39 \mathrm{~d}$ \\
$\mathrm{AM}$ & $17,49 \mathrm{~b}$ & $5,20 \mathrm{bc}$ & $0,81 \mathrm{c}$ & $76,49 \mathrm{c}$ \\
$\mathrm{AM}+\mathrm{BE}$ & $18,13 \mathrm{~b}$ & $5,54 \mathrm{~b}$ & $0,90 \mathrm{bc}$ & $77,73 \mathrm{bc}$ \\
$\mathrm{AC}$ & $18,06 \mathrm{~b}$ & $6,86 \mathrm{~b}$ & $1,08 \mathrm{~b}$ & $89,71 \mathrm{~b}$ \\
$\mathrm{AC}+1-\mathrm{MCP}$ & $26,57 \mathrm{a}$ & $8,39 \mathrm{a}$ & $1,38 \mathrm{a}$ & $108,99 \mathrm{a}$ \\
\hline $\mathrm{CV}(\%)$ & 14,4 & 7,4 & 10,0 & 4,8 \\
\hline
\end{tabular}

Médias seguidas pela mesma letra na vertical não diferem entre si, pelo teste de Tukey $(\mathrm{p}<0,05)$. AR: atmosfera refrigerada $(21 \mathrm{kPa}$ $\mathrm{O}_{2}+<0,03 \mathrm{kPa} \mathrm{CO}_{2}$ ); AM: atmosfera modificada (PEBD perfurado com absorvedor de $\mathrm{CO}_{2}$, com 2,5 $\mathrm{kPa} \mathrm{O}_{2}+<0,1 \mathrm{kPa} \mathrm{CO}$ ); $\mathrm{AC}$ : atmosfera controlada $\left(1 \mathrm{kPa} \mathrm{O}_{2}+1 \mathrm{kPa} \mathrm{CO}_{2}\right)$ BE: baixo etileno; e 1-MCP: 1-metilciclopropeno $\left(1 \mu \mathrm{L} \mathrm{L}^{-1}\right)$.

TABELA 3 - Índice de cor vermelha (ICV), cor da epiderme, acidez titulável, degenerescência de polpa e cor da polpa em ameixas 'Laetitia', após 60 dias em diferentes sistemas de armazenamento refrigerado $\left(0,5 \pm 0,1^{\circ} \mathrm{C} / 95 \pm 2 \% \mathrm{UR}\right)$, seguido de três dias em condição ambiente $\left(20 \pm 2^{\circ} \mathrm{C} / 60 \pm 5 \% \mathrm{UR}\right)$.

\begin{tabular}{|c|c|c|c|c|c|}
\hline $\begin{array}{l}\text { Sistema de } \\
\text { armazenamento }\end{array}$ & $\begin{array}{l}\mathrm{ICV} \\
(1-4)\end{array}$ & $\begin{array}{c}\text { Cor da epiderme } \\
\qquad\left(h^{\circ}\right)\end{array}$ & $\begin{array}{l}\text { Acidez titulável } \\
\left(\text { meq } 100 \mathrm{~mL}^{-1}\right)\end{array}$ & $\begin{array}{l}1 \text { Degenerescência } \\
\text { de polpa }(\%)\end{array}$ & $\begin{array}{c}\text { Intensidade de } \\
\text { escurecimento da polpa }(L)\end{array}$ \\
\hline \multicolumn{6}{|c|}{ Saída da câmara } \\
\hline $\mathrm{AR}$ & $3,41 \mathrm{a}$ & $56,97 \mathrm{~b}$ & - & - & - \\
\hline $\mathrm{AM}$ & $2,93 \mathrm{~b}$ & $71,16 \mathrm{a}$ & - & - & - \\
\hline $\mathrm{AM}+\mathrm{BE}$ & $2,93 \mathrm{~b}$ & $68,69 \mathrm{a}$ & - & - & - \\
\hline $\mathrm{AC}$ & $2,85 \mathrm{~b}$ & $69,61 \mathrm{a}$ & - & - & - \\
\hline $\mathrm{AC}+1-\mathrm{MCP}$ & $2,77 b$ & $73,42 \mathrm{a}$ & - & - & - \\
\hline $\mathrm{CV}(\%)$ & 8,3 & 8,4 & - & - & - \\
\hline \multicolumn{6}{|c|}{ Após 3 dias em temperatura ambiente } \\
\hline $\mathrm{AR}$ & $3,94 a$ & $40,22 b$ & $5,90 \mathrm{~b}$ & 100,0 & $41,30 \mathrm{c}$ \\
\hline $\mathrm{AM}$ & $3,34 \mathrm{~b}$ & $64,71 \mathrm{a}$ & $6,19 b$ & 100,0 & $39,54 \mathrm{c}$ \\
\hline $\mathrm{AM}+\mathrm{BE}$ & $3,54 \mathrm{~b}$ & $64,61 \mathrm{a}$ & $7,32 \mathrm{ab}$ & 100,0 & $48,69 \mathrm{ab}$ \\
\hline $\mathrm{AC}$ & $3,33 \mathrm{~b}$ & $64,87 \mathrm{a}$ & $6,14 \mathrm{~b}$ & 100,0 & $44,00 \mathrm{abc}$ \\
\hline $\mathrm{AC}+1-\mathrm{MCP}$ & $3,46 \mathrm{~b}$ & $64,91 \mathrm{a}$ & $8,53 a$ & 100,0 & $50,52 \mathrm{a}$ \\
\hline$\overline{\mathrm{CV}}(\%)$ & 6,1 & 4,6 & 9,8 & 0,00 & 8,0 \\
\hline
\end{tabular}

Médias seguidas pela mesma letra na vertical não diferem entre si, pelo teste de Tukey $(\mathrm{p}<0,05)$.AR: atmosfera refrigerada $(21 \mathrm{kPa}$ $\mathrm{O}_{2}+<0,03 \mathrm{kPa} \mathrm{CO}_{2}$ ); $\mathrm{AM}$ : atmosfera modificada (PEBD perfurado com absorvedor de $\mathrm{CO}_{2}$, com $2,5 \mathrm{kPa} \mathrm{O}+<0,1 \mathrm{kPaCO}$ ); $\mathrm{AC}_{2}$ atmosfera controlada $\left(1 \mathrm{kPa} \mathrm{O}_{2}+1 \mathrm{kPa} \mathrm{CO}_{2}\right)$ BE: baixo etileno; e 1-MCP: 1-metilciclopropeno $\left(1 \mu \mathrm{L} \mathrm{L}^{-1}\right)$. 


\section{CONCLUSÕES}

1-A atmosfera controlada retarda o amadurecimento de ameixas 'Laetitia'. Além disso, a associação desse sistema de armazenamento com o uso do 1-MCP apresenta melhores resultados.

2-O manejo do etileno, tanto em atmosfera modificada ativa como em atmosfera controlada, reduz a severidade da degenerescência da polpa em ameixas 'Laetitia', evidenciando o efeito do etileno no desenvolvimento do distúrbio.

3-O armazenamento com manejo do etileno confere maior aceitabilidade dos consumidores às ameixas 'Laetitia', quanto à cor e ao sabor.

\section{AGRADECIMENTOS}

Os autores agradecem ao Conselho Nacional de Desenvolvimento Científico e Tecnológico (CNPq), ao Programa de Apoio da Universidade do Estado de Santa Catarina (UDESC) e à Fundação de Amparo à Pesquisa e Desenvolvimento Científico e Tecnológico de Santa Catarina (FAPESC) pelo apoio finaceiro.

\section{REFERÊNCIAS}

ALVES, E.O.; STEFFENS, C.A.; AMARANTE, C.V.T.; PAVANELLO, E.P.; BRACKMANN, A. Manejo do etileno durante o armazenamento de ameixas 'Laetitia' em atmosfera controlada. Ciência Rural, Santa Maria, v.39, n.9, p.2445-245, 2009a.

ALVES, E.O.; STEFFENS, C.A.; AMARANTE, C.V.T.; WEBER, A.; MIQUELOTO, A.; BRACKMANN, A. Armazenamento refrigerado de ameixas 'Laetitia' com uso de 1-MCP e indução de perda de massa fresca. Ciência Rural, Santa Maria, v.40, n.1, p.30-36, 2009b.

AMARANTE, C.V.T.; STEFFENS, C.A. Sachês absorvedores de etileno na pós-colheita de maçãs 'Royal Gala'. Revista Brasileira de Fruticultura, Jaboticabal, v.31, n.1, p.071-077, 2009.

ARGENTA, L.C.; MATTHEIS, J.; FAN, X. Retardamento da maturação de maçãs 'Fuji' pelo tratamento com 1-MCP e manejo da temperatura. Revista Brasileira de Fruticultura, Jaboticabal, v.23, n.2, p.270-273, 2001.
ARGENTA, L.C.; KRAMMES, J.|G.; MEGGUER, C.A.; AMARANTE, C.V.T.; MATTHEIS, J. Efeitos da inibição da ação do etileno na maturação e qualidade de ameixas 'Laetitia' após a colheita e armazenagem refrigerada . Pesquisa Agropecuária Brasileira, Brasília, v.38, n.10, p.1139-1148, 2003.

BLANKENSHIP, S.M.; DOLE, J.M. 1-Methylcyclopropene: a review. Postharvest Biology and Technology, Amsterdam, v.28, n.1, p.1-25, 2003.

BRACKMANN, A.; BENEDETTI, M.; HUNSCHE, M.; SESTARI, I. Armazenamento de ameixas cvs. Reubennel e Pluma 7 sob diferentes temperaturas, em atmosfera controlada e refrigerada. Revista Brasileira de Agrociência, Pelotas, v.11, n.1, p.85-89, 2005a.

BRACKMANN, A.; FREITAS, S.T.; MELLO, A.M.; STEFFENS, C.A. Aplicação de 1-MCP em caqui 'Quioto' armazenado sob refrigeração e atmosfera controlada. Revista Brasileira de Fruticultura, Jaboticabal, v.25, n.1, p.42-44, 2003.

BRACKMANN, A.; GUARIENTI, A.J.W.; SAQUET, A.A.; GIEHL, R.F.H.; SESTARI, I. Condições de atmosfera controlada para maçã 'Pink Lady'. Ciência Rural, Santa Maria, v.35, n.3, p.504-509, 2005b.

BRACKMANN, A.; SESTARI, I.; STEFFENS, C.A.; GIEHL, R.F.H.Qualidade de maçãs cv. Gala tratada comm 1-Metilciclopropeno. Ciência Rural, Santa Maria, v. 34, n.5, p.1415-1420, 2004.

BRACKMANN, A.; STEFFENS, C.A.; GIEHL, R.F.H. Armazenamento de pêssegos 'Chimarrita' em atmosfera controlada e sob absorção de etileno. Ciência Rural, Santa Maria, v.33, n.3, p.431-435, 2003.

GORNY, J.R.; KADER, A.A. The mode of $\mathrm{CO}_{2}$ action on ACC oxidase and its role in inhibition of ethylene biosynthesis. HortScience, Alexandria, v.29, n.5, p.533, 1994.

JACOMINO, A.P.; KLUGE, R.A.; BRACKMANN, A.; CASTRO, P.R.C. Amadurecimento e senescência de mamão com 1-metilciclopropeno. Scientia Agrícola, Piracicaba, v.59, n.2, p.303-308, 2002.

KHAN, A.S.; SINGH, Z. 1-MCP application suppresses ethylene biosynthesis and retards fruit softening during cold storage of 'Tegan Blue' Japanese plum. Plant Science, Amsterdam, v.176, n.4, p.539-544, 2009. 
LUO, Z.; XIE, J.; XU, T.; ZHANG, L. Delay ripening of 'Qingnai' plum (Prunus salicina Lindl.) with 1-methylcyclopropene. Plant Science, Amsterdam, v.177, n.3, p.705-709, 2009.

MANGANARIS, G.A.; VICENTE, A.R.; CRISOSTO, C.H.; LABAVITCH, J.M. Cell wall modifications in chilling-injured plum fruit (Prunus salicina). Postharvest Biology and Technology, Amsterdam, v.48, n.1, p.77-83, 2008.

MENNITI, A.M.; DONATI, I.; GREGORI, R. Responses of 1-MCP application in plums stored under air and controlled atmospheres. Postharvest Biology and Technology, Amsterdam, v.39, n.3, p.243-246, 2006.

NAVA, G.A.; BRACKMANN, A. Armazenamento de pêssegos (Prunus persica (L.) Batsch), cv. Chiripá, em atmosfera controlada. Revista Brasileira de Fruticultura, Jaboticabal, v.24, n.2, p.328-332, 2002.

PEDRESCHI, R.; FRANCK, C.; LAMMERTYN, J.; ERBAN, A.; KOPKA, J.; HERTOG, M.; VERLINDEN, B.; NICOLAI, B. Metabolic profiling of 'Conference' pears under low oxygen stress. Postharvest Biology and Technology, Amsterdam, v.50, n.2, p.123-130, 2009.
SAQUET, A.A.; STREIF, J. Respiração e produção de etileno de maçãs armazenadas em diversas concentrações de oxigênio. Revista Brasileira de Agrociência, Pelotas, v.8, n.1, p.71-75, 2002.

SAQUET, A.A.; STREIF, J.; BANGERTH, F. Energy metabolism and membrane lipid alterations in relation to brown heart development in 'Conference' pears during delayed controlled atmosphere storage. Postharvest Biology and Technology, Amsterdam, v.30, n.2, p.123-132, 2003.

SAS INSTITUTE. Getting started with the SAS learning edition. Cary: SAS Institute, 2002. 200p.

STEFFENS, C.A.; BRACKMANN, A.; PINTO, J.A.V.; EISERMANN, A.C. Taxa respiratória de frutas de clima temperado. Pesquisa Agropecuária Brasileira, Brasília, v.42, n.3, p.313-321, 2007.

STEFFENS, C.A.; AMARANTE, C.V.T.; ALVES, E.O.; TANAKA, H.; BRACKMANN, A.; BOTH, V. Armazenamento de ameixas 'Laetitia' em atmosfera modificada. Ciência Rural, Santa Maria, v.39, n.9, p.2439-2444, 2009.

WILLS, R.B.H.; WARTON, M.A. Efficacy of potassium permanganate impregnated into alumina beads to reduce atmospheric ethylene. Journal of the American Society for Horticultural Science, Alexandria, v.129, n.3, p.433-438, 2004. 